\section{Do parents of children with caries choose to opt out of positive consent dental surveys in Wales?}

\author{
N. P. Monaghan, ' S. J. Jones² and M. Z. Morgan ${ }^{3}$
}

VERIFIABLE CPD PAPER

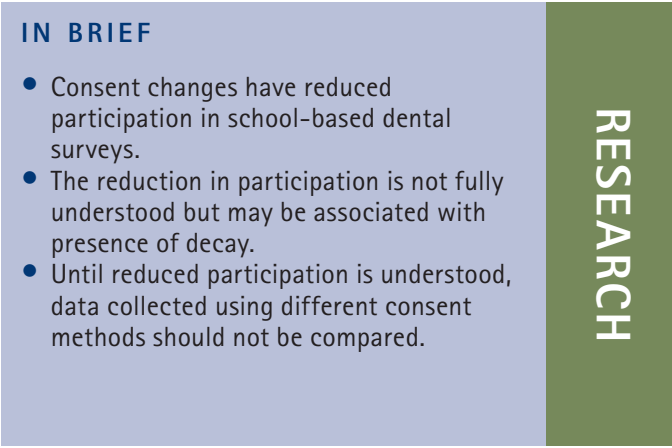

\begin{abstract}
Background Recently, positive consent has been required for dental surveys in some parts of the UK. Concerns have been raised that when positive consent is used participation is reduced in deprived areas and reported caries levels are biased as a consequence. This paper analyses caries data collected under positive and negative consent arrangements to explore this issue further. Method Retrospective analysis of response rates by deprivation fifth and by caries experience of participating children in NHS coordinated dental surveys in Wales undertaken from 2001/2 until 2005/6 using negative consent and in 2007/8 using positive consent. Results Across Wales, the change from negative to positive consent was associated with greatly decreased participation. In comparison with previous surveys there was a large increase in children sampled but not examined. The decrease in the proportion of children sampled, who were examined and found to have no decay was similar across all deprivation fifths, with no obvious deprivation-related trend. There was a much larger reduction in the number of children with decay who participated across all quintiles of deprivation. Conclusion Caries status could be a more important factor than deprivation regarding opting out of the survey. It appears that children with caries are more likely to be opted out of the survey than similarly deprived peers without caries. Parents appear to be more likely to opt children with caries out of dental surveys when positive consent is used. These findings have significant implications for targets aimed at improving oral health which were set before the change in consent procedures, but reported upon after.
\end{abstract}

\section{BACKGROUND}

Since 2006, in England, ${ }^{1}$ Wales $^{2}$ and Northern Ireland, ${ }^{3}$ it has been deemed inappropriate for five-year-old children to undergo school-based dental examinations without positive written parental consent. Before 2006, standard practice was to send a letter home to parents stating that the child would be examined unless the parents refused. This practice was underpinned by laws stating that children should be encouraged to have dental and medical examinations in school settings provided parents had not refused.

\footnotetext{
${ }^{1 *}$ Consultant in Dental Public Health, ${ }^{2}$ Locum Consultant in Public Health, Public Health Wales, Temple of Peace, Cathays Park, Cardiff, CF10 3NW; ${ }^{3}$ Public Health Specialist and Lecturer in Dental Public Health, Applied Clinical Research and Public Health, Cardiff University School of Dentistry, Heath Park, Cardiff, CF14 4XY

${ }^{*}$ Correspondence to: Mr Nigel Monaghan

Email: nigel.monaghan@wales.nhs.uk
}

\section{Refereed Paper}

Accepted 4 April 2010

DOI: 10.1038/sj.bdj.2011.26

${ }^{\circ}$ British Dental Journal 2011: E1
This process was commonly referred to as 'negative consent'.

Concerns exist that dental data collected using positive consent may be biased. ${ }^{4,5}$ This has implications for monitoring trends in oral health over time across the United Kingdom. In Scotland, in 2000/1 questions were raised by Local Authority staff about data sharing necessary to draw samples for the survey programme. This resulted in the data in some areas of Scotland being collected using negative consent, but data in other areas being collected using positive consent. Scotland did not publish results for surveys of children aged 12 and five for the years 2000/1 and 2001/2 respectively. ${ }^{6,7}$ It was anecdotally reported by those close to the Scottish programme that parents in more deprived households were less likely to respond to letters sent home from school. It was suggested that this created substantial differences in participation according to the consent method used. For a negative consent letter, children in deprived areas would be less likely to be 'opted out', but for a positive consent survey they are less likely to be 'opted in'. Decay levels are known to be higher in deprived communities in the $\mathrm{UK}^{8}$ so if deprived children are 'opted out' of the survey reported decay levels would be expected to fall, particularly in deprived communities, which they did. The differential response rate in 2000/1 was sufficient to make oral health comparisons between Scottish Health Boards using different forms of consent meaningless.

Similar issues have been highlighted in England. Anderson noted a drop in participation to $78 \%$ from an estimated $90 \%$ in participation when required to use positive consent in 1993. ${ }^{5}$ Positive consent used for local surveys in the West Midlands resulted in participation levels as low as $49 \% .^{4}$ Unquantified reductions in participation using positive consent were found in the Bradford area in 2005/6. ${ }^{9}$

In postal surveys the use of positive consent is more likely to lead to nonresponse bias and affect reported numbers of decayed, missing and filled teeth. ${ }^{10}$ This study aims to explore whether the changed 


\begin{tabular}{|c|c|c|c|c|c|c|c|c|c|}
\hline \multirow[b]{2}{*}{ Fifth } & \multicolumn{2}{|l|}{$2001 / 2$} & \multicolumn{2}{|l|}{$2003 / 4$} & \multicolumn{2}{|l|}{$2005 / 6$} & \multicolumn{2}{|l|}{$2007 / 8$} & \multirow{2}{*}{$\begin{array}{l}\text { Difference in proportions: } \\
2007 / 8 \text { versus } 2005 / 6\end{array}$} \\
\hline & Sampled & $\%$ seen & Sampled & $\%$ seen & Sampled & $\%$ seen & Sampled & $\%$ seen & \\
\hline Least deprived & 205 & $87.3 \%$ & 252 & $87.7 \%$ & 144 & $87.5 \%$ & 204 & $60.3 \%$ & $-27.2 \%(-18.1 \%$ to $-35.4 \%)$ \\
\hline Second least deprived & 246 & $91.1 \%$ & 145 & $89.7 \%$ & 157 & $89.8 \%$ & 184 & $60.3 \%$ & $-29.5 \%(-20.6 \%$ to $-37.6 \%)$ \\
\hline Middle deprived & 331 & $88.2 \%$ & 384 & $90.6 \%$ & 397 & $86.9 \%$ & 342 & $54.4 \%$ & $-32.5 \%(-26.2 \%$ to $-38.6 \%)$ \\
\hline Second most deprived & 365 & $89.3 \%$ & 461 & $91.8 \%$ & 400 & $89.0 \%$ & 408 & $55.4 \%$ & $-33.6 \%(-27.7 \%$ to $-39.2 \%)$ \\
\hline Most deprived & 546 & $88.5 \%$ & 524 & $86.8 \%$ & 533 & $79.5 \%$ & 486 & $46.3 \%$ & $-33.3 \%(-27.5 \%$ to $-38.7 \%)$ \\
\hline Total sampled (all fifths) & \multicolumn{2}{|l|}{1693} & \multicolumn{2}{|l|}{1766} & \multicolumn{2}{|l|}{1631} & \multicolumn{2}{|l|}{1624} & Average sampled: 1678.5 \\
\hline Chi-squared test for trend & \multicolumn{2}{|l|}{0.008} & \multicolumn{2}{|l|}{0.154} & \multicolumn{2}{|l|}{11.097} & \multicolumn{2}{|l|}{14.533} & \\
\hline$p$-value & \multicolumn{2}{|l|}{0.93} & \multicolumn{2}{|l|}{0.695} & \multicolumn{2}{|l|}{0.001} & \multicolumn{2}{|l|}{$<0.001$} & \\
\hline
\end{tabular}

Significant values shown in bold $\left(x^{2}\right.$ test)

consent arrangements in Wales had a similar effect on participation in the clinical examination school dental survey of 2007/8. Given previous reports of reduced participation and reduced decay scores when positive consent was used for clinical dental surveys, this study also starts to further explore the relationship between consent-associated changes in response rates, deprivation and decay experience.

\section{METHOD}

Sampling was undertaken in line with the British Association for the Study of Community Dentistry (BASCD) epidemiology sampling guidance. ${ }^{11}$ Examiners reported on visual signs of caries $\left(\mathrm{d}_{3} \mathrm{mft}\right)$ in the deciduous dentition in line with BASCD standards. ${ }^{12}$ These data have been collected on a biannual basis in Wales since $1985 / 6 .{ }^{13}$ The change in consent arrangements occurred in 2006, before planning for the 2007/8 survey. However, the approach to sampling and the survey itself was the same in $2007 / 8$ as in the previous survey in 2005/6. In Wales data collection for the NHS surveys is completed by the end of April each year. The legal advice to use positive consent only for these surveys was issued in Wales after April 2006, and had no impact on data collection in 2005/6.

The sampling frame is designed to sample approximately 250 children from the smallest Unitary Authority (UA) in Wales, Merthyr Tydfil, which has a population of 58,000. Similar proportions are then drawn from all other UAs in Wales. Schools are stratified into small and large based on

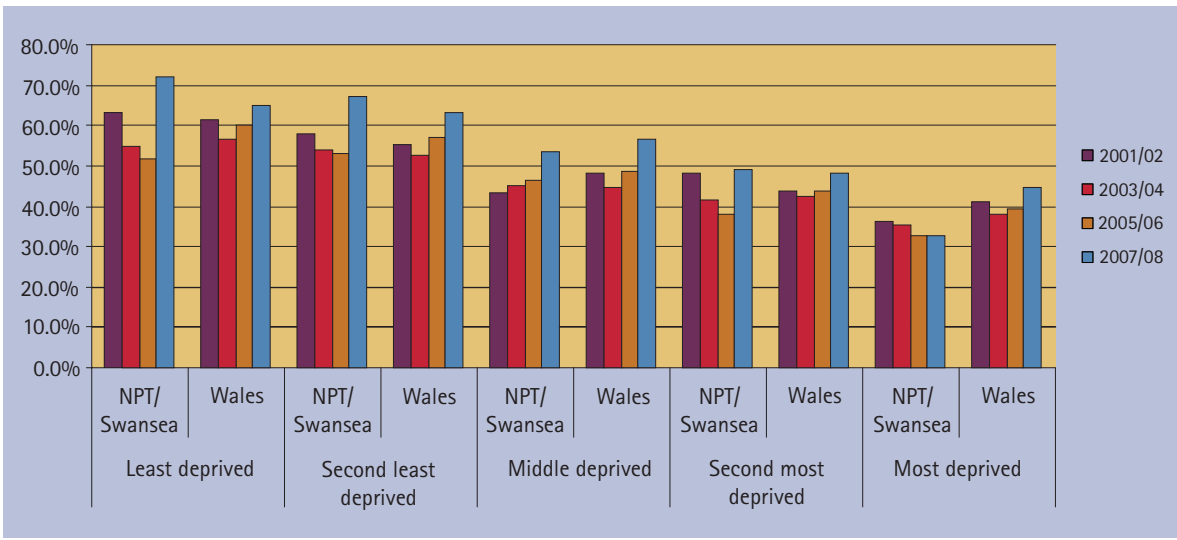

Fig. 1 Proportion of examined five-year-old children caries-free by deprivation, for Swansea and Neath Port Talbot and Wales, across four surveys

the numbers on roll and schools from each stratum are randomly selected to generate the required sample size in line with the BASCD criteria. ${ }^{14}$

Data were analysed for Swansea and Neath Port Talbot combined and for all Wales for 2001/2, 2003/4, 2005/6 and 2007/8. Swansea and Neath Port Talbot data were analysed because detailed data on the sampling frame, participation and, most importantly, consent were available at the school level. Such detailed information was not available for the rest of Wales. Comparison of caries for Swansea and Neath Port Talbot and all Wales was used as an indicator of whether consentrelated issues were similar across the whole country.

School postcode was used to assign each child to a deprivation fifth. Presence or absence of caries and severity of caries was calculated for each fifth for each time period for Swansea/Neath Port Talbot and for all Wales. Schools were assigned to fifths of deprivation based on the Townsend index of deprivation for Wales ${ }^{15}$ for the electoral division in which the school was located.

For each time period, deprivation fifth and for each geographical level, the proportion of children with no caries was calculated, along with the trend in the proportion with no caries by fifth of deprivation ( $\chi^{2}$ test for trend). Differences in proportions and 95\% confidence intervals were calculated between 2005/6 and $2007 / 8$.

\section{RESULTS}

As Table 1 demonstrates in Swansea and Neath Port Talbot, an average of 1678.5 children were sampled to participate in each survey. Participation dropped significantly across all fifths of deprivation in these areas between 2005/6 and 2007/8. The drop increased with increasing deprivation, from $27.2 \%$ (95\% CI $18.1 \%$ to $35.4 \%$ ) among the least deprived, to 33.3\% (95\% CI $27.5 \%$ to $38.7 \%$ ) among the most 


\begin{tabular}{|c|c|c|c|c|c|c|c|c|c|}
\hline & \multicolumn{2}{|c|}{$2001 / 2$} & \multicolumn{2}{|c|}{$2003 / 4$} & \multicolumn{2}{|c|}{$2005 / 6$} & \multicolumn{2}{|c|}{$2007 / 8$} & \multirow{2}{*}{$\begin{array}{l}\text { Difference in proportions } \\
2007 / 8 \text { versus } 2005 / 6\end{array}$} \\
\hline & $\mathrm{n}$ & $\%$ of sampled & $n$ & $\%$ of sampled & $n$ & $\%$ of sampled & $n$ & $\%$ of sampled & \\
\hline Total sampled & 1693 & & 1766 & & 1631 & & 1624 & & \\
\hline \multirow[t]{2}{*}{ Not examined } & 197 & $11.6 \%$ & 201 & $11.4 \%$ & 259 & $15.9 \%$ & 741 & $45.6 \%$ & $29.8 \%$ (26.7\% to $32.7 \%)$ \\
\hline & & $\%$ with no $d_{3} \mathrm{mft}$ & & $\%$ with no $d_{3} \mathrm{mft}$ & & $\%$ with no $d_{3} \mathrm{mft}$ & & $\%$ with no $d_{3} \mathrm{mft}$ & $2007 / 8$ versus $2005 / 6$ \\
\hline Total examined & 1496 & $47.5 \%$ & 1565 & $43.5 \%$ & 1372 & $41.3 \%$ & 883 & $51.4 \%$ & $10.2 \%(6.0 \%$ to $14.3 \%)$ \\
\hline Least deprived & 219 & $63.0 \%$ & 221 & $54.8 \%$ & 126 & $51.6 \%$ & 136 & $72.1 \%$ & $20.5 \%(8.7 \%$ to $31.5 \%)$ \\
\hline Second least deprived & 227 & $57.7 \%$ & 130 & $53.8 \%$ & 141 & $53.2 \%$ & 101 & $67.3 \%$ & $14.1 \%(1.6 \%$ to $25.9 \%)$ \\
\hline Middle deprived & 270 & $43.3 \%$ & 334 & $45.2 \%$ & 321 & $46.4 \%$ & 195 & $53.3 \%$ & $6.9 \%(-2.0 \%$ to $15.6 \%)$ \\
\hline $\begin{array}{l}\text { Second most } \\
\text { deprived }\end{array}$ & 354 & $48.3 \%$ & 449 & $41.4 \%$ & 385 & $37.9 \%$ & 222 & $49.1 \%$ & $11.2 \%(3.0 \%$ to $19.2 \%)$ \\
\hline Most deprived & 426 & $36.2 \%$ & 431 & $35.5 \%$ & 399 & $32.8 \%$ & 229 & $32.8 \%$ & $0.0 \%(-7.5 \%$ to $7.6 \%)$ \\
\hline $\begin{array}{l}\text { Chi-squared test } \\
\text { for trend }\end{array}$ & \multicolumn{2}{|l|}{46.3} & \multicolumn{2}{|l|}{28.7} & \multicolumn{2}{|l|}{28.7} & \multicolumn{2}{|l|}{63.3} & \\
\hline$p$-value & \multicolumn{2}{|c|}{$<0.001$} & \multicolumn{2}{|c|}{$<0.001$} & \multicolumn{2}{|c|}{$<0.001$} & \multicolumn{2}{|c|}{$<0.001$} & \\
\hline
\end{tabular}

Significant values shown in bold $\left(x^{2}\right.$ test)

\section{Table 3 Numbers sampled, examined and with no $\mathrm{d}_{3} \mathrm{mft}$, by deprivation fifth in Wales}

\begin{tabular}{|c|c|c|c|c|c|c|c|c|c|}
\hline \multirow{2}{*}{$\begin{array}{l}\text { Wales } \\
\text { Fifth }\end{array}$} & \multicolumn{2}{|c|}{$2001 / 2$} & \multicolumn{2}{|c|}{$2003 / 4$} & \multicolumn{2}{|c|}{$2005 / 6$} & \multicolumn{2}{|c|}{$2007 / 8$} & \multirow{2}{*}{$\begin{array}{l}\text { Difference in proportions } \\
2007 / 8 \text { versus } 2005 / 6\end{array}$} \\
\hline & $\mathrm{n}$ & $\%$ with no $\mathrm{d}_{3} \mathrm{mft}$ & $\mathrm{n}$ & $\%$ with no $\mathrm{d}_{3} \mathrm{mft}$ & $\mathrm{n}$ & $\%$ with no $d_{3} \mathrm{mft}$ & $\mathrm{n}$ & $\%$ with no $d_{3} \mathrm{mft}$ & \\
\hline Total examined & 10836 & $48.8 \%$ & 11147 & $46.5 \%$ & 10496 & $48.9 \%$ & 7,071 & $55.9 \%$ & $7.0 \%(5.5 \%$ to $8.5 \%)$ \\
\hline Least deprived & 1868 & $61.6 \%$ & 2281 & $56.7 \%$ & 1770 & $60.2 \%$ & 1473 & $64.8 \%$ & $4.6 \%(1.3 \%$ to $7.9 \%)$ \\
\hline Second least deprived & 1782 & $55.3 \%$ & 1785 & $52.6 \%$ & 1842 & $56.9 \%$ & 1378 & $63.4 \%$ & $6.4 \%(3.0 \%$ to $9.8 \%)$ \\
\hline Middle deprived & 2002 & $48.1 \%$ & 2281 & $44.7 \%$ & 2240 & $48.6 \%$ & 1539 & $56.5 \%$ & $7.9 \%(4.6 \%$ to $11.6 \%)$ \\
\hline Second most deprived & 2374 & $43.7 \%$ & 2381 & $42.3 \%$ & 2324 & $43.6 \%$ & 1545 & $48.3 \%$ & $4.7 \%(1.5 \%$ to $7.9 \%)$ \\
\hline Most deprived & 2810 & $41.0 \%$ & 2419 & $38.2 \%$ & 2320 & $39.4 \%$ & 1136 & $44.8 \%$ & $5.4 \%(1.9 \%$ to $8.9 \%)$ \\
\hline $\begin{array}{l}\text { Chi-squared test } \\
\text { for trend }\end{array}$ & 239.5 & & 203.8 & & 242.4 & & 163.4 & & \\
\hline$p$-value & $<0.00$ & & $<0.00$ & & $<0.00$ & & $<0.00$ & & \\
\hline
\end{tabular}

Significant values shown in bold $\left(x^{2}\right.$ test)

deprived, but with overlapping confidence intervals the difference between fifths of deprivation is unlikely to be significant (Table 1).

Between 2001/02 and 2005/06 in Swansea and Neath Port Talbot, on average, 1477 children were examined, while in 2007/08, when positive consent was introduced, just 883 were examined (Table 2). The proportion of examined children in Swansea and Neath Port Talbot with no visually decayed, missing or filled teeth ( $\mathrm{d}_{3} \mathrm{mft}$ ) rose significantly between 2005/06 and 2007/08 (difference in proportions $10.2 \%$, 95\% CI $6.0 \%$ to $14.3 \%$; Table 2). However, the proportion of children who were sampled but not examined rose by almost a third, a significant increase (29.8\%, 95\% CI 32.7\% to 26.7\%). Patterns across the deprivation fifths were not consistent, with wide confidence intervals indicating the lack of precision in the point estimate (see Table 2).

The proportions of examined five-yearold children judged visually caries-free by deprivation fifth $\left(\% \mathrm{~d}_{3} \mathrm{mft}=0\right)$ for Swansea and Neath Port Talbot and Wales show increases in the less deprived quintiles in 2007/8 compared with previous surveys (Fig. 1). For all Wales in 2007/8 compared with 2005/6, the proportion of visually caries free children rose across all five quintiles of deprivation. This does not reflect the trend of previous surveys (see Table 3). The estimated increases in 2007/8 compared with 2005/6 ranged from 4.6\% to $7.9 \%$ (see last column of Table 3 ).

\section{DISCUSSION}

Among the children who were examined there was a significant increase in the proportion of five-year-olds with no $\mathrm{d}_{3} \mathrm{mft}$ in 2007/8 compared with 2005/6 across all deprivation fifths (except the most deprived quintile in Swansea and Neath Port Talbot) and across the whole of Wales. The new guidance on consent for school-based dental surveys was introduced without warning. 
Ideally, before any change in legal interpretation was implemented, parallel surveys using positive and negative consent could have been undertaken to understand and quantify the impact of changed consent on participation in a range of circumstances. The introduction of positive consent was associated with greatly reduced participation and larger than expected reductions in average $d_{3} m f t$ indices. Reductions over this short timescale are greater than what would be expected if water fluoridation had been introduced. ${ }^{16}$ The Scottish experience in 2000-2002 suggested that parents of children in deprived areas are less likely to participate in a dental survey than more affluent peers.

Analyses to date have not explored reasons for lower levels of participation. Actions resulting in increased nonresponse include passively opting out (not bothering to read or send back a form sent to the home), and active non-response (making a decision to exclude the child from the survey, for example by deciding not to send a form to school or by sending a form refusing). Reasons for lower participation in all communities could reflect parents not bothering to reply or could be caused by parents deliberately excluding children because the children have caries experience and the parents know it. If the latter is the case then it could have implications for strategies intended to raise the participation rate when positive consent is used. If non-participation is related only to deprivation-associated passive opting out, then it would be expected that:

- the drop in participation would

be greatest among more deprived communities

- within all fifths of deprivation the drop in participation of children with and children without decay should be similar.

However, if non-participation is related mainly to decay experience then the drop in participation would be greater in those children expected to have caries. This would be seen in all quintiles of deprivation but have a greater effect on $\mathrm{d}_{3} \mathrm{mft}$ scores in more deprived areas because of the increased caries prevalence in those communities.

The data presented here suggests that children with decay are much more likely to be excluded than caries-free peers. There were small falls in participation of cariesfree children, so it is likely that some parents of children simply do not bother to opt in using positive consent. However, the fall in participation of children with decay appears to be much larger than for peers without decay. This suggests that many parents of children with decayed teeth are actively choosing not to participate in the surveys. Reasons for this could include a desire to avoid parental or child embarrassment. Actively opting out appears to be the main reason for non-participation, and further research involving parents not consenting to the dental examination could explore these issues further.

Given that the objective of dental surveys is to estimate the true prevalence and severity of decay in the population, active decisions by parents to exclude children with decay will result in under-reporting. The level of under-reporting is significant enough to make comparisons of reported dental health using data collected with different types of consent inappropriate.

If the evidence suggested similar drops in participation levels for children with and without caries in each quintile of deprivation then it would be possible to boost the population weightings given to the deprived quintiles. The analyses in this paper suggest that such an approach would be inappropriate. More needs to be understood about the true caries status of nonresponders before reweighted data could be produced.

In the meantime given problems of comparability of data it is recommended that data collected in the NHS coordinated dental epidemiology surveys should report on the participation rate and the type of consent used. This will not facilitate direct comparison of data collected with different methods but could provide a visible warning that data is dissimilar.

\section{Limitations}

One key limitation of these analyses is the use of the school postcode to assign children to a deprivation fifth. Ideally, the residential postcode would be used. Previous research in Wales has shown that the Townsend score for the electoral division in which a primary school is located is strongly correlated with the proportion of free school meals received by children attending that school. ${ }^{17}$ Obtaining accurate home postcode from the child or school may be difficult. Given that this is a study of five-year-olds in Wales, it is likely that the home to school distance is short and that this is unlikely to result in significant movement between deprivation fifths as a result of the discrepancy between the two places.

Participation data for Swansea and Neath Port Talbot are used to make assumptions about the rest of Wales, based on the similarity in decay experience between Swansea and Neath Port Talbot and Wales. It is possible that this assumption is flawed, but it seems unlikely.

Data is not available to indicate the number of children who did not participate because of a formal refusal as opposed to simply not responding. However, this paper raises concerns about the apparent disproportionate non-participation of children likely to have decayed teeth, whether parents are formally or informally declining participation. Even if data was available on those parents who formally or informally declined, the parents would not have to indicate reasons for declining. The possibility that caries status is a factor would remain. The absence of actual data on non-responders means it cannot be stated with certainty whether parents are aware of child caries status and that this affects their response to a positive consent letter. This analysis does suggest that caries status may be more important than deprivation and this is worthy of further investigation.

\section{CONCLUSIONS}

Use of positive consent does reduce participation across all quintiles of deprivation but it appears that participation is reduced most for children with caries experience. Because caries is more prevalent in deprived areas the impact on participation and $\mathrm{d}_{3} \mathrm{mft}$ scores is greater there. These findings have significant implications for oral health targets which were set before the change in consent procedures, but reported upon after.

\section{Recommendations}

The hypothesis that many parents are likely to be aware their children have decay and that some of these parents decide to exclude their children from dental 
surveys merits further investigation. In the meantime it is recommended that:

- Data collected in the NHS coordinated dental epidemiology surveys be tagged to identify the type of consent used and the response or participation rate

- Further research be undertaken with non-responders to positive consent dental surveys to explore reasons for non-participation including parental knowledge of child caries status.

The authors would like to thank the Welsh Assembly Government for funding the survey programme and $\mathrm{Mr}$ William Challacombe for providing sampling data for Swansea and Neath Port Talbot.

1. Department of Health. Consent for school dental inspections and dental epidemiological surveys. London: Department of Health, 2006. http://www. dh.gov.uk/assetRoot/04/13/55/32/04135532.pdf. Accessed 29 November 2010.

2. Welsh Assembly Government. Welsh Health Circular 052. Consent for school dental inspections and dental epidemiological surveys. Cardiff: Welsh Assembly Government, 2006. http://www.wales.nhs. uk/documents/WHC_(2006)_052.pdf. Accessed 29 November 2010

3. Department of Health, Social Services and Public Safety. Consent for school dental inspections and dental epidemiological surveys. Belfast: Department of Health, Social Services and Public Safety, 2006. http://www.dhsspsni.gov.uk/consent notice 2006 12.pdf. Accessed 29 November 2010.

4. White D A, Morris A J, Hill K B, Bradnock G. Consent and school-based surveys. Br Dent J 2007; 202: 715-717.

5. Anderson R J. Changes in dental caries experience of 12-year-old children in two Somerset schools: a review after an interval of 30 years. Br Dent J 1995 179: $125-129$

6. Pitts N B, Evans D J, Nugent Z J, Pine C M. The denta caries experience of 12-year-old children in England and Wales. Surveys coordinated by the British Association for the Study of Community Dentistry in 2000/2001. Community Dent Health 2002: 19: 46-53.

7. Pitts N B, Boyles J, Nugent Z J, Thomas N, Pine C M The dental caries experience of 5 -year-old children in England and Wales. Surveys coordinated by the British Association for the Study of Community Dentistry in 2001/2002. Community Dent Health 2003; 20: 45-54.

8. O'Brien M. Children's dental health in the United Kingdom 1993. London: Her Majesty's Stationery Office, 1994.

9. Dyer T A, Marshman Z, Merrick D, Wyborn C Godson J H. School-based epidemiological surveys and the impact of positive consent requirements. BrDent J 2008; 205: 589-592.

10. Tickle M, Milson K M, Blinkhorn A S, Worthington $\mathrm{H}$ V. Comparing different methods to detect and correct nonresponse bias in postal questionnaire studies. J Public Health Dent 2003; 63: 112-118.

11. Pine C M, Pitts N B, Nugent Z J. British Association for the Study of Community Dentistry (BASCD) guidance on sampling for surveys of child dental health. A BASCD coordinated dental epidemiology programme quality standard. Community Dent Health 1997; 14 (suppl 1): 10-17.

12. Pitts N B, Fyffe H E. The effect of varying diagnostic thresholds upon clinical caries data for a low caries prevalence group. J Dent Res 1988; 67: 592-596.

13. Dowell T B. The caries experience of 5-year-old children in England and Wales. A survey coordinated by the British Association for the Study of Community Dentistry in 1985-86. Community Dent Health 1988; 5: 185-197.

14. Pine C M, Pitts N B, Nugent Z J. British Association for the Study of Community Dentistry (BASCD) guidance on the statistical aspects of training and calibration of examiners for surveys of child denta health. A BASCD coordinated dental epidemiology programme quality standard. Community Dent Health 1997; 14 (Suppl 1): 18-29.

15. National Public Health Service for Wales. Townsend index of deprivation for Wales. Cardiff: National Public Health Service for Wales, 2003. http:// www.wales.nhs.uk/sites3/documents/368 TOWNSEND2001 walesedivfifthsmap2.xls. Accessed online 29 November 2010

16. McDonagh $\mathrm{M}$, Whiting $\mathrm{P}$, Bradley $\mathrm{M}$ et al. A systematic review of public water fluoridation. York: The University of York NHS Centre for Reviews and Dissemination, 2000. Report 18. http://www. york.ac.uk/inst/crd/fluores.htm. Accessed 29 November 2010.

17. Jones S J. Child pedestrian injuries and deprivation: a study of data sources, exposure and the road traffic environment. Cardiff: University of Cardiff, 2004 $\mathrm{PhD}$ thesis. 